\title{
ENHANCING BIOGAS PRODUCTION OF MEAT INDUSTRIAL WASTEWATER BY MICROWAVE PRETREATMENT
}

\author{
Róbertné Kovács*, Gábor Keszthelyi-Szabó, Péter Szendrő \\ Department of Process Engineering, Faculty of Engineering, University of Szeged, \\ 9. Moszkvai krt.H-6725 Szeged, Hungary; e-mail: veszelov@mk.u-szeged.hu
}

\section{Abstract}

The effects of microwave pre-treatment of meat industrial wastewater were investigated in this study. The focus of this investigation was to determine the optimum conditions in a continuous flow microwave treating system under which the microwave pre-treatment of meat industrial wastewater would facilitate the maximum biogas yield. Response surface analysis was applied to screen the effects of volumetric flow rate (FR), number of treating (NT) and power of the magnetron (PM).

Keywords: pretreatment, biogas, microwave, anaerobic digestion

\section{Introduction}

Every areas of economy produce liquid, solid or gaseous pollutions. Applying sewage without any pretreatment is harmful for the receiving environment in many ways. It can exacerbate such effects as exhaustion of oxygen in the receiving waters, reduction of natural regenerating capacity, the formation of bad odours and eventually the death of aquatic life. Besides, wastewater frequently contains pathogenic bacteria, nutrients and toxic compounds such as heavy metals. For these reasons, it is inevitable to use sewage treatment, to develop applied technologies, and to introduce new methods. A very important portion of sewage treatment is the removal of organic matter present in soluble and particulate form in wastewater. Anaerobic digestion (AD) is an efficient process both for the treatment of wastewater and the energy recovery.

This process is biological degradation by a complex microbial consortium of organic substrates in the absence of oxygen. $\mathrm{AD}$ reduces the pathogen content, stabilizes the wastewater and reduces the volume to be disposed without any addition of chemicals with only the action of other type of bacteria. During the process, organic matter is converted, mainly, to methane, carbon dioxide and more biomass. This process is very attractive because besides not needing any added chemical reagents, no oxygen is required, it can produce a usable form of energy, as methane gas such that in certain cases, an energy surplus can be obtained. 
$\mathrm{AD}$ is a series of parallel and sequential metabolic processes, performed by a variety of microbiological consortia. This process contains four main steps (Batstone, 1999): hydrolysis, acidogenesis, acetogenesis, and methanogenesis. Hydrolysis is considered as the limiting step in the anaerobic degradation. In this step, larger particles and or insoluble particles are degraded into smaller and more degradable forms.

Wastewater is mainly comprised of microbial cells and extracellular polymeric substances (EPS) produced by the cells as part of their metabolic activity. These contents form a matrix that is the substrate for the anaerobic digestion. Most of the EPS (proteins and carbohydrates) are negatively charged. Binding of EPS with positively charged cations increases the strength of the structure. In respect of their physical state, microbial cells represent a relatively unfavourable substrate for subsequent microbial degradation. A large part of the organic matter is compartmentalized within the microbial cell membranes. The cell envelope of microorganisms is a semi-rigid structure providing sufficient intrinsic strength to protect the cell from osmotic lysis. This microbial cell wall contains glycan strands cross-linked by peptide chains that give the walls resistance to biodegradation. Therefore for achieving acceptable biodegradation rate conventional biological digestion techniques require long hydraulic retention times. The efficiency of digestion can be increased by disrupting the microbial cells and making organic matter inside the cell walls available. (Pavlostathis and Giraldo-Gomez, 1991).

Disintegration may be performed by chemical, thermal, mechanical, biological or by a combination of these techniques. (Adel et al., 2010; Fernandes et al., 2009; Mosier et al., 2005; Sun and Cheng, 2002)

The pre-treatment also has the goal of decreasing the particle size, allowing a greater surface area per unit volume available for degradation (Muller et al., 2004).

This paper deals with one of the thermal pre-treatment: microwave. In microwave processing, energy is supplied by an electromagnetic field directly to the material. Volumetric heating can be accomplished in shorter processing time and more economically compared with conventional heating. In addition heating occurs instantly and throughout the whole sample, heating can be controlled instantly, heat concentrates in the materials that have a high dielectric factor (selectivity). (Hong, 2002)

The microwave field and the dielectric response of a material govern its ability to heat with microwave energy (Thostenson and Chou, 1999). The behaviour of a sample subject to microwave heating is depending on its chemical and physical properties. The most important properties are the dielectric loss factor, the dielectric constant and the dissipation factor. 
Several studies were carried out on matter solubilisation by microwave previous to anaerobic digestion. After the microwave pretreatment, the total biogas production improved, and the microwave irradiation additionally decreased the initial lag-phase of anaerobic digestion (Beszédes et al., 2011; Jackowiak et al., 2011).

\section{Materials and Methods}

Meat industrial wastewater was collected in a Hungarian medium-sized meat processing company; the sampling point was after the grease tap. Sewage originates from meat processing technology, mainly from the flushing and rinsing process of equipment (slicing and packaging machines, smoking chambers). To remove grit, particles and other large-sized solids a cloth filter was used.

Table 1: Characteristics of wastewater

\begin{tabular}{|c|c|}
\hline Parameter & Value \\
\hline Total solid (TS) $\left(\mathrm{mgL}^{-1}\right)$ & $3210 \pm 296$ \\
\hline $\begin{array}{c}\text { Total organic carbon }(\mathrm{TOC}) \\
\left(\mathrm{mgL}^{-1}\right)\end{array}$ & $834,1 \pm 35,3$ \\
\hline $\begin{array}{c}\left.\text { Lipid( } \mathrm{mgL}^{-1}\right) \\
\text { Protein }\left(\mathrm{mgL}^{-1}\right)\end{array}$ & $115,1 \pm 21,7$ \\
\hline
\end{tabular}

\section{Microwave pre-treating system}

Microwave pre-treating system (Fig. 1) contains a water-cooled, variable-power magnetron (M) operating at $2450 \mathrm{MHz}$. High-voltage power supply (NF power supply) feeding the magnetron consists of two transformers, one of them produces cathode heating voltage and heating current, the other produces the anode voltage which can be controlled by the primary circuit of an external auto-transformer. With this device (PM scaled TTR) the power of the magnetron can be set as well. Electromagnetic energy of the magnetron spread over a resonant slot. Getting through this slot the energy gets in the toroidal resonator. (Kovács et al, 2012). During the operation of toroid resonator energy is given to the treated material. As a result of energy transmission the temperature of the material rises and the dielectric properties change continuously. The effect of the microwave energy intake, variable power, impedance and dielectric relationships are formed in the microwave resonator. Some of these can be measured (eg. power dissipation, reflected power), some of them can only be determined by calculation, knowledge of the other parameters (J. Zhu et al, 2007). Material is transferred in the continues-flow microwave treating system by a peristaltic pump (PP) with variable flow. 


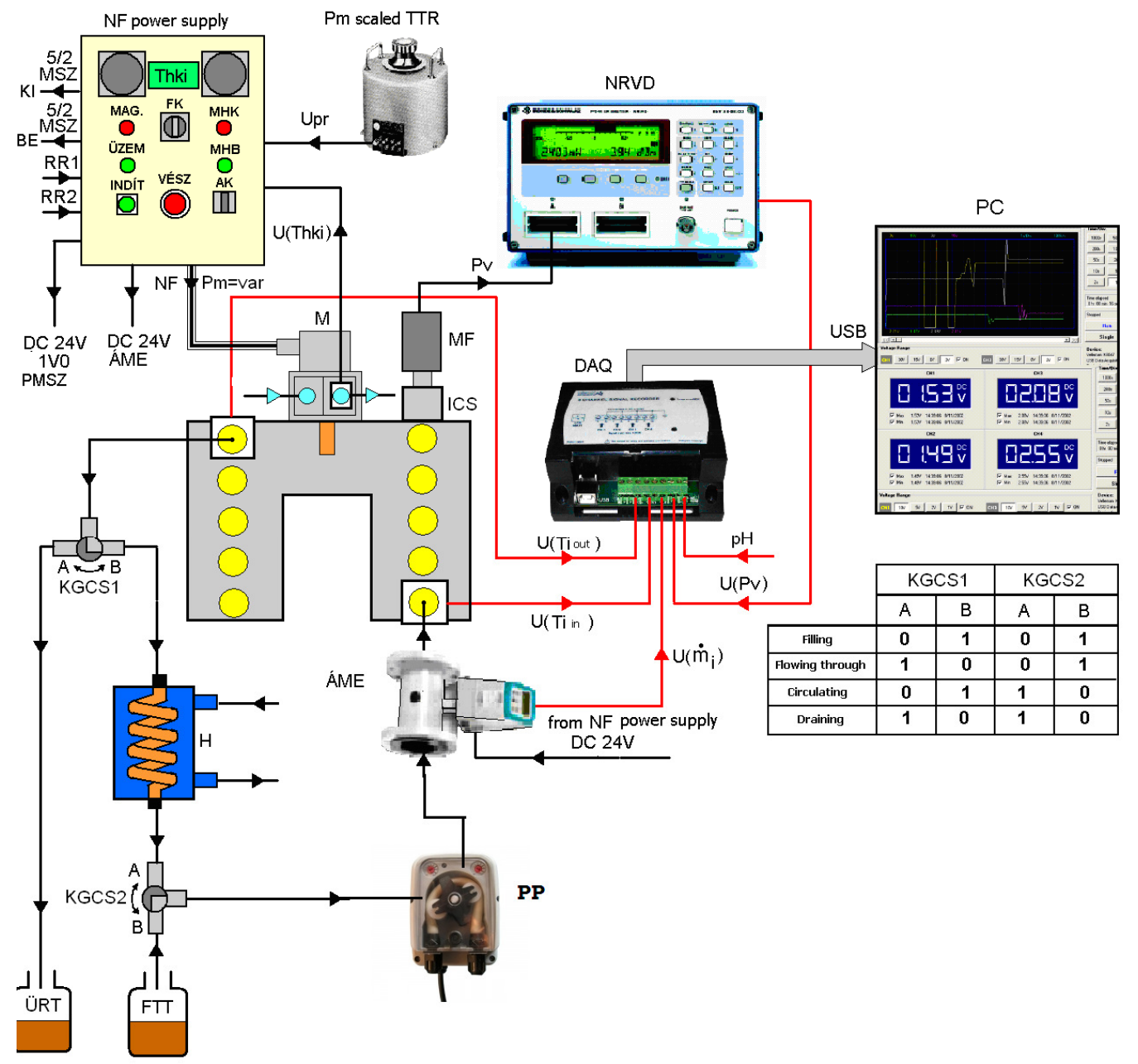

Fig. 1: Microwave pre-treating system

\section{Fermentation process, biogas measurement}

Anaerobic digestion (AD) tests were carried out under controlled mesophilic temperature range $\left(35 \pm 0,2^{\circ} \mathrm{C}\right)$. in 12 mini continuously stirred laboratory scale reactors with $250 \mathrm{~mL}$ total volume, equipped with Oxitop C.

\section{Experimental design}

A factorial design was used in order to test all the conditions and possible interactions between PM, FR and NT. Treatments were carried out at different PM, at different FR, and different NT. Three levels from these parameters were used and combined (Table 3). The method of least squares was used to estimate the coefficients. The values used in the experimental design are given in Table 2. 
Table 2: Factorial design of the experiment

\begin{tabular}{|c|c|c|c|}
\hline & \multicolumn{3}{|c|}{ Factors } \\
\hline Level & $\begin{array}{c}\text { Power of the } \\
\text { magnetron (PM) } \\
{[\mathbf{W}]}\end{array}$ & $\begin{array}{c}\text { Flow rate (FR) } \\
{\left[\mathbf{L h}^{-1}\right]}\end{array}$ & $\begin{array}{c}\text { Number of treatings } \\
\text { (NT) } \\
{[-]}\end{array}$ \\
\hline- & 300 & 6 & 1 \\
\hline 0 & 500 & 15,5 & 3 \\
\hline+ & 700 & 25 & 5 \\
\hline
\end{tabular}

Table 3: Assignment of operational parameters in the $2^{p}$ factorial design

\begin{tabular}{|c|c|c|c|}
\hline \multirow{2}{*}{ Run } & \multicolumn{3}{|c|}{ Factors } \\
\hline $\begin{array}{c}\text { Power of the } \\
\text { magnetron } \\
{[\mathbf{W}]}\end{array}$ & $\begin{array}{c}\text { Flow rate } \\
{\left[\mathbf{L h}^{-1}\right]}\end{array}$ & $\begin{array}{c}\text { Number of treatings } \\
{[\mathbf{d b}]}\end{array}$ \\
\hline 1 & + & + & + \\
\hline 2 & + & + & - \\
\hline 3 & + & - & + \\
\hline 4 & - & + & + \\
\hline 5 & - & - & + \\
\hline 6 & - & + & - \\
\hline 7 & + & - & 0 \\
\hline 8 & - & - & 0 \\
\hline 9 & 0 & 0 & 0 \\
\hline 10 & 0 & 0 & + \\
\hline 11 & 0 & & 0 \\
\hline
\end{tabular}

To evaluate energetically pretreatment process specific energy demand (SED) was determined.

$$
S E D=\frac{E}{B P}
$$

where $\mathrm{BP}$ is biogas production, $\mathrm{E}$ is the energy demand of pretreatments was calculated from the power of the magnetron $\left(\mathrm{P}_{\mathrm{M}}\right)$ and the time of irradiation $(\mathrm{t})$.

$$
E=P_{M} \cdot t
$$


The aim of this study was to screen the effects of PM, the FR and NT by the use of a composite design. Response surface analysis was used to represent the linkage between the response SED (Y) and experimental variables (PM $\left(\mathrm{X}_{1}\right)$, FR $\left(\mathrm{X}_{2}\right)$, NT $\left.\left(\mathrm{X}_{3}\right)\right)$. Relationship can be written as function of variables,

$$
\begin{gathered}
Y=a_{0}+a_{1} \cdot X_{1}+a_{2} \cdot X_{2}+a_{3} \cdot X_{3}+a_{12} \cdot X_{1} \cdot X_{2}+a_{13} \cdot X_{1} \cdot X_{3}+a_{23} \cdot X_{2} \cdot X_{3} \\
+a_{123} \cdot X_{1} \cdot X_{2} \cdot X_{3}
\end{gathered}
$$

where $a_{0}, a_{1}, a_{2}, a_{3}, a_{12}, a_{13}, a_{23}$ are coefficients.

\section{Effect of FR, NT and PM on biogas yield}

The aim of this study to define the effects of microwave treatment on wastewater for enhancing biogas yield.

The effects of microwave pre-treatment on biodegradation were investigated with a composite experimental design. FR, NT, PM profiles are shown in Table 4 with the associated response which is SED. Results were correlated as function of FR, NT, PM (Eq. (3), Table 5) and represented with response surfaces (Fig. 2). The 30-day trial version of Design-Expert ${ }^{\circledR}$ software was used for data processing.

Table 4: PM, FR, NT used in the composite design and response associated.

\begin{tabular}{|c|c|c|c|c|c|c|}
\hline No. & $\begin{array}{c}\text { PM [W] } \\
\mathbf{X}_{\mathbf{1}}\end{array}$ & $\begin{array}{c}\mathbf{F R}_{\mathbf{2}}\left[\mathbf{L h}^{-1}\right] \\
\mathbf{X}_{\mathbf{2}}\end{array}$ & $\begin{array}{c}\mathbf{N T}[-] \\
\mathbf{X}_{\mathbf{3}}\end{array}$ & $\mathbf{t}[\mathbf{s}]$ & $\mathbf{E}[\mathbf{J}]$ & SED [ $\left.\frac{\boldsymbol{J}}{\boldsymbol{m l}}\right]$ \\
\hline 1 & 700 & 25 & 5 & 360 & 252000 & 845 \\
\hline 2 & 700 & 25 & 1 & 72 & 50400 & 183 \\
\hline 3 & 700 & 6 & 1 & 300 & 210000 & 646 \\
\hline 4 & 300 & 25 & 5 & 360 & 108000 & 420 \\
\hline 5 & 300 & 6 & 5 & 1500 & 450000 & 1510 \\
\hline 6 & 300 & 25 & 1 & 72 & 21600 & 87 \\
\hline 7 & 700 & 6 & 5 & 1500 & 1050000 & 3125 \\
\hline 8 & 300 & 6 & 1 & 300 & 90000 & 310 \\
\hline 9 & 500 & 15,5 & 3 & 348 & 174000 & 642 \\
\hline 10 & 500 & 15,5 & 3 & 348 & 174000 & 651 \\
\hline 11 & 500 & 15,5 & 3 & 348 & 174000 & 644 \\
\hline
\end{tabular}

Table 5: Coefficients values of equations representing the response surfaces of SED as function of FR, NT, PM.

\begin{tabular}{|c|c|c|}
\hline \multicolumn{2}{|c|}{ Variables } & \multirow{2}{*}{ Values of coefficients } \\
\hline Coefficients & Name & $-833,26$ \\
\hline $\mathrm{a}_{0}$ & Constant & 1,5 \\
\hline $\mathrm{a}_{1}$ & PM $\left(\mathrm{X}_{1}\right)$ & 46,64 \\
\hline $\mathrm{a}_{2}$ & FR $\left(\mathrm{X}_{2}\right)$ & 314,57 \\
\hline $\mathrm{a}_{3}$ & NT $\left(\mathrm{X}_{3}\right)$ & $-0,094$ \\
\hline $\mathrm{a}_{12}$ & PM $\mathrm{FR}$ & 0,5 \\
\hline $\mathrm{a}_{13}$ & PM $\times \mathrm{NT}$ & $-17,66$ \\
\hline $\mathrm{a}_{23}$ & FR $\times$ NT & \\
\hline
\end{tabular}



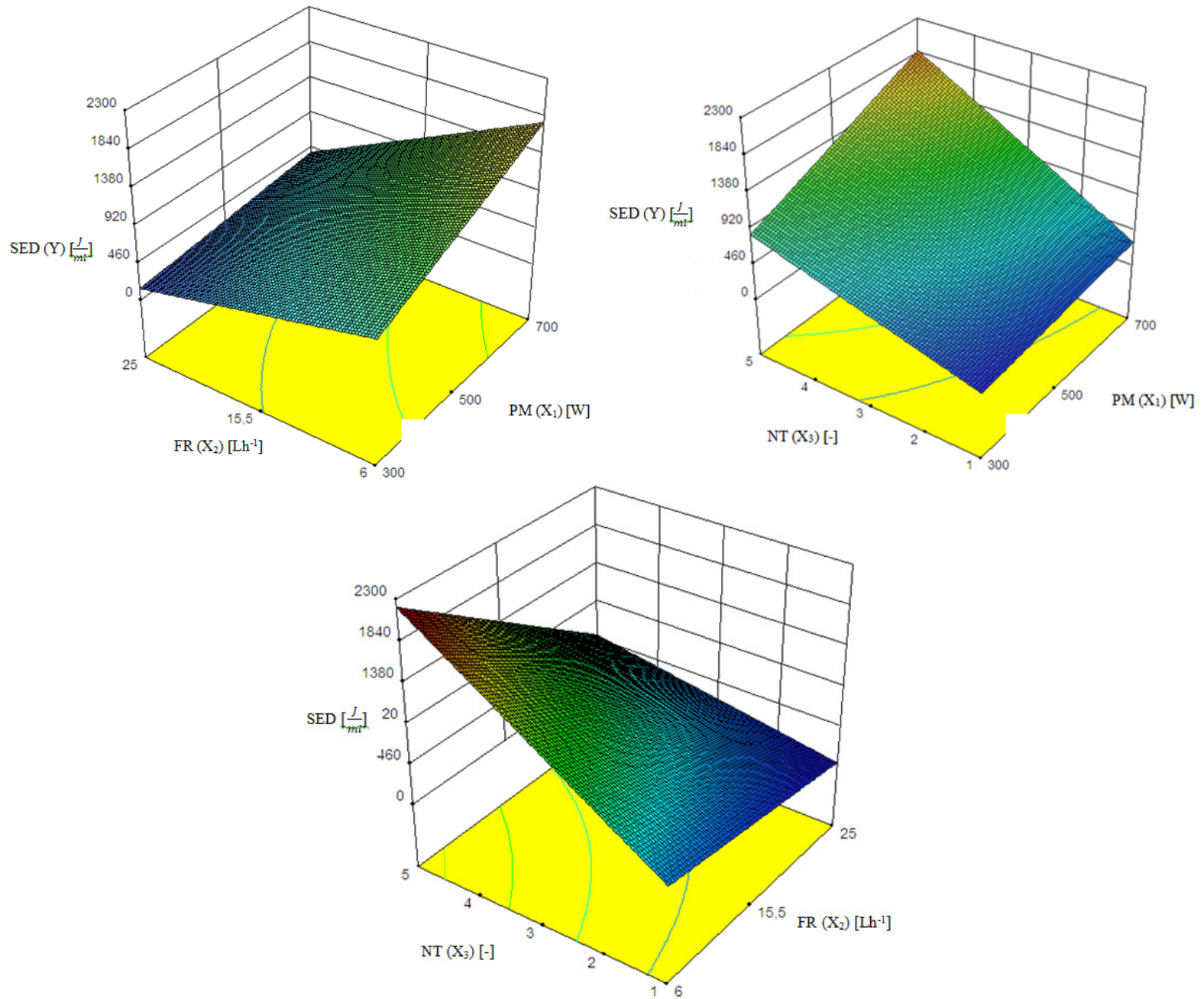

Fig. 2: The response surfaces of SED as function of PM, FR, NT

The approximate mathematical model of SED is as follows

$$
\begin{gathered}
S E D=-833,26+1,5 \cdot P M+46,64 \cdot F R+314,57 \cdot N T-0,094 \cdot P M \cdot F R+0,5 \\
\cdot P M \cdot N T-17,66 \cdot F R \cdot N T
\end{gathered}
$$

In case of energy demand such as SED, the aim of optimization is to minimize its value. Accordingly from table 4, the optimal setting is No.6. As shown, this model for SED is a function of three input variables individually and the interaction between them. Fig. 3 shows the predictive capability of the model. The predictive figure shows the correlation between the actual and predicted data and the accuracy of fitting. 


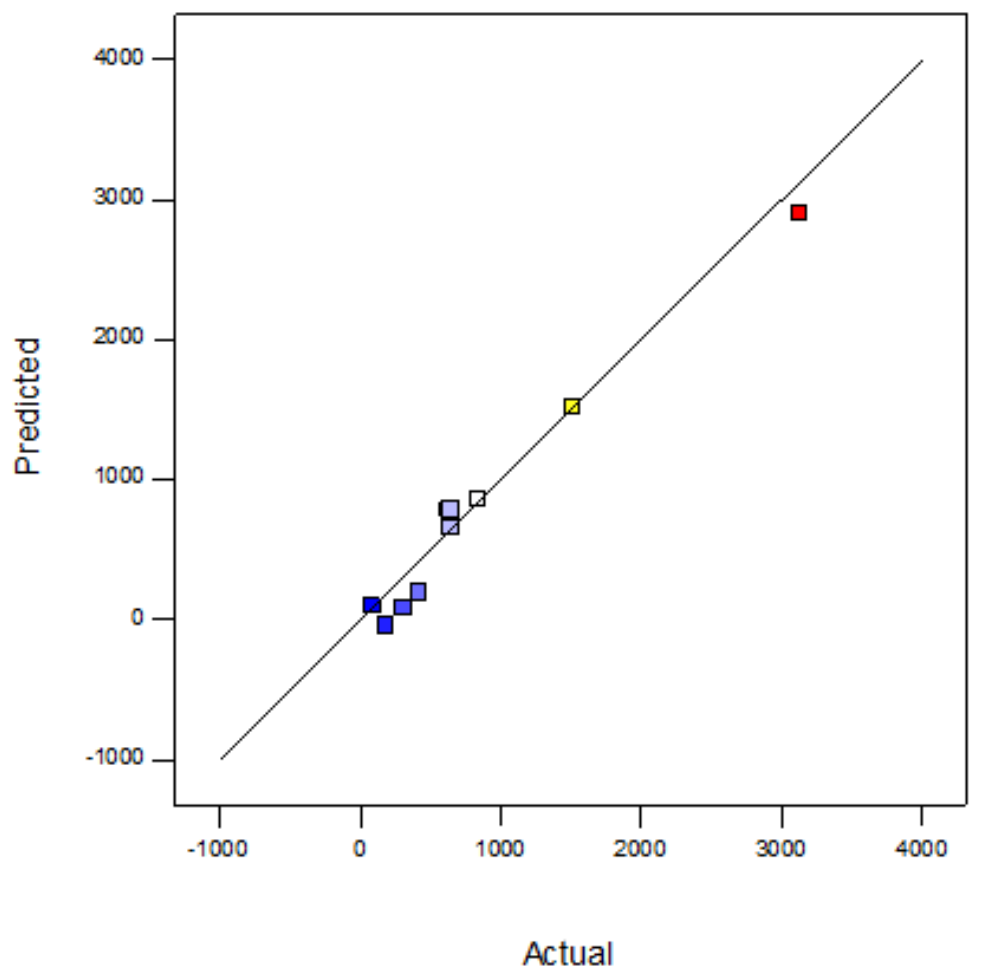

Fig. 3: Predicted vs. actual datas

PM, FR, and NT and interactions have a statistically significant effect on SED as can be seen in the ANOVA Table 6. In case of PMxFRxNT p-value $>>0,05$, this interaction is not a significant term.

Table 6: ANOVA table for SED

\begin{tabular}{|l|l|l|l|l|l|}
\hline \multicolumn{1}{|c|}{ Source } & \multicolumn{1}{|c|}{$\begin{array}{c}\text { Sum of } \\
\text { Squares }\end{array}$} & \multicolumn{1}{|c|}{ df } & \multicolumn{1}{c|}{$\begin{array}{c}\text { Mean } \\
\text { Square }\end{array}$} & \multicolumn{1}{|c|}{ F } & p-value \\
\hline Model & $7,030 \mathrm{E}+006$ & 6 & $1,172 \mathrm{E}+006$ & 25,44 & 0,0002 \\
\hline PM $\left(\mathrm{X}_{1}\right)$ & $7,638 \mathrm{E}+005$ & 1 & $7,638 \mathrm{E}+005$ & 16,59 & 0,0047 \\
\hline FR $\left(\mathrm{X}_{2}\right)$ & $2,056 \mathrm{E}+006$ & 1 & $2,056 \mathrm{E}+006$ & 44,65 & 0,0003 \\
\hline NT $\left(\mathrm{X}_{3}\right)$ & $2,731 \mathrm{E}+006$ & 1 & $2,731 \mathrm{E}+006$ & 59,30 & 0,0001 \\
\hline PM x FR & $2,556 \mathrm{E}+005$ & 1 & $2,556 \mathrm{E}+005$ & 5,55 & 0,0506 \\
\hline PM x NT & $3,232 \mathrm{E}+005$ & 1 & $3,232 \mathrm{E}+005$ & 7,02 & 0,0330 \\
\hline FR x NT & $9,005 \mathrm{E}+005$ & 1 & $9,005 \mathrm{E}+005$ & 19,55 & 0,0031 \\
\hline Error & 249,33 & 5 & 49,87 & & \\
\hline
\end{tabular}

Regression algorithms are more robust, precise and show fewer round off and multicollinearity errors when variables are coded and centered, so PM, FR and NT values were codified (PM', FR' and NT') according to expressions (5), (6) and (7), even though they could not be exactly centered:

$$
X_{n}^{\prime}=\frac{X_{n}-X_{n}^{0}}{\Delta X_{n}}
$$




$$
\begin{gathered}
X_{n}^{0}=\frac{X_{n}^{\max }+X_{n}^{\min }}{2} \\
\Delta X_{n}=\frac{X_{n}^{\max }-X_{n}^{\min }}{2}
\end{gathered}
$$

Regression model initially considered as (3), becomes (8), using the coded variables

$$
Y=a_{0}{ }^{\prime}+a_{1}{ }^{\prime} \cdot X_{1}{ }^{\prime}+a_{2}{ }^{\prime} \cdot X_{2}{ }^{\prime}+a_{3}{ }^{\prime} \cdot X_{3}{ }^{\prime}+a_{12}{ }^{\prime} \cdot X_{1}{ }^{\prime} \cdot X_{2}{ }^{\prime}+{a_{13}}{ }^{\prime} \cdot X_{1}{ }^{\prime} \cdot X_{3}{ }^{\prime}+a_{23}{ }^{\prime} \cdot X_{2}{ }^{\prime} \cdot X_{3}{ }^{\prime}
$$

Table 7: Estimated coefficients (along with $95 \%$ confidence intervals) for SED as a function

\begin{tabular}{|c|c|c|c|c|c|}
\hline Coefficient & Coefficient & df & Standard & $\mathbf{9 5 \%}$ Cl & $\mathbf{9 5 \%}$ Cl \\
\cline { 5 - 6 } & Value & & Error & Low & High \\
\hline $\mathrm{a}_{0}$, & 784,86 & 1 & 57,35 & 649,23 & 920,48 \\
\hline $\mathrm{a}_{1}$, & 309,00 & 1 & 75,87 & 129,59 & 488,41 \\
\hline $\mathrm{a}_{2}$, & $-507,00$ & 1 & 75,87 & $-686,41$ & $-327,59$ \\
\hline $\mathrm{a}_{3}$ & 584,25 & 1 & 75,87 & 404,84 & 763,66 \\
\hline $\mathrm{a}_{12}$ & $-178,75$ & 1 & 75,87 & $-358,16$ & 0,66 \\
\hline $\mathrm{a}_{13}$ & 201,00 & 1 & 75,87 & 21,59 & 380,41 \\
\hline $\mathrm{a}_{23}$ & $-335,50$ & 1 & 75,87 & $-514,91$ & $-156,09$ \\
\hline
\end{tabular}

\section{Conclusion}

The results of Table 4 are used to create a response surface in order to obtain the output variables of the propulsion model as a mathematical function of the three input variables and the interaction between them. Therefore, in every desired value of PM, FR and NT, output variables can be computed.

\section{References}

Adel, A.M., Abd El-Wahab, Z.H., Ibrahim, A.A., Al-Shemy, M.T., 2010. Characterization of microcrystalline cellulose prepared from lignocellulosic materials: Part I. Acid catalyzed hydrolysis. Bioresour. Technol. 101, 4446-4455.

Batstone, D.J., (1999), High rate anaerobic treatment of complex wastewater, Ph.D. thesis, University of Queensland, Brisbane, Australia.

Beszédes, S., Laszlo, Z., Horvath, Z.H., Szabo, G., Hodur, C., 2011. Comparison of the effects of microwave irradiation with different intensities on the biodegradability of sludge from the dairy- and meat-industry. Bioresour. Technol. 102, 814-821.

Fernandes, T.V., Klaasse Bos, G.J., Zeeman, G., Sanders, J.P.M., Van Lier, J.B., 2009. Effects of thermo-chemical pre-treatment on anaerobic biodegradability and hydrolysis of lignocellulosic biomass. Bioresour. Technol. 100, 2575-2579.

Hong, Seung-Mo, (2002), Enhancement of pathogen destruction and anaerobic digestibility using microwaves, PhD Thesis, University of Wisconsin-Madison, USA.

Jackowiak, D., Frigon, J.C., Ribeiro, T., Pauss, A., Guiot, S., 2011. Enhancing solubilisation and methane production kinetic of switchgrass by microwave pretreatment. Bioresour. Technol. 102, 3535-3540.

Kovács P V R, Beszédes S, Ludányi L, Hodúr C, Szabó G (2012),Development of a continuous flow microwave toroidal cavity resonator 11th INTERNATIONAL 
SCIENTIFIC CONFERENCE MMA 2012: ADVANCED PRODUCTION TECHNOLOGIES, Novi Sad: University of Novi Sad, 2012. pp. 357-360.

Mosier, N., Wyman, C., Dale, B., Elander, R., Lee, Y.Y., Holtzapple, M., Ladisch, M., 2005. Features of promising technologies for pretreatment of lignocellulosic biomass. Bioresour. Technol. 96, 673-686.

Muller, J., Lehne, G., Schwedes, J., Battenberg, S., Naveke, R., Kopp, J., Dichtl, N., et al. (1998). Disintegration of sewage sludges and influence on anaerobic digestion. Water Science and Technology, 38(8-9), 425-433.

Pavlostathis, S., Giraldo-Gomez, E., (1991), Kinetics of anaerobic treatment, Water Science and Technology, 24(8), 35-59.

Sun, Y., Cheng, J., 2002. Hydrolysis of lignocellulosic materials for ethanol production: a review. Bioresour. Technol. 83, 1-11.

E. T. Thostenson and T-W. Chou, "Microwave Processing: Fundamentals and Applications," Composites Part A, 30(9): 1055-1071 (1999).

J. Zhu, A.V. Kuznetsov, K.P. Sandeep (2007) „Mathematical modeling of continuous flow microwave heating of liquids", International Journal of Thermal Sciences, Vol. 46, 328341 